Proc. Indian Acad. Sci., Vol. 87 A (E \& P Sciences-4), No. 11, November 1978, pp. 231-234, (C) printed in India

\title{
Solar x-ray control of the ionospheric absorption measured by the sweep frequency method*
}

\author{
G P GUPTA \\ Applied Physics Section, Institute of Technology, Banaras Hindu University, \\ Varanasi 221005
}

MS received 28 March 1978; revised 12 June 1978

\begin{abstract}
The ionospheric absorption data measured by the sweep frequency method have been compared with the solar $x$-ray data in the band of $1-8 \hat{A}$ during quiet- and disturbed-sun conditions. The degree of solar $x$-ray control of the ionospheric absorption and the corresponding limit of solar $x$-ray flux have been discussed.
\end{abstract}

Keywords. Control; absorption; sweep frequency method.

\section{Introduction}

The day-time formation of lower ionosphere ( $D$-region) is the result of various ionisation sources such as; solar $X$-rays of wavelength less than $10 \AA$, solar Lyman $a$-radiation and $1108 \AA$ radiation. The contribution from different ionisation sources has been a debatable problem over the last many years and is left uncertain todate. Various workers (Triska and Lastovicka 1970; Ganguly 1972; Deshpande et al 1972, Lastovicka 1973; Kotadia et al 1976; Rao and Ramana 1977) have studied the influence of solar $\mathrm{x}$-ray on the ionospheric absorption by comparing the well-known A1, A2 and A3 absorption data with the solar X-ray data. Many of them have discussed about the threshold value of solar $x$-ray fiux for controlling the ionospheric absorption. During the quiet-sun conditions when the absorption is not controlled by the solar x-ray, the control of the absorption is generally attributed to solar Lyman a-radiation. In the present paper, the solar $\mathrm{x}$-ray control of the ionospheric absorption measured by the sweep frequency method has been investigated during the quiet- and disturbed-sun conditions. The sweep frequency method is now having obvious advantages over the well-known A1, A2 and A3 methods. The sweep frequency method measures the intensity variation of various radio signals transmitted in certain frequency band and reflected from the ionospheric layers. The details of sweep frequency method and its working have been described elsewhere (Ilias and Gupta 1978).

Since 1968, the ionospheric absorption in the frequency band of $6.3-10.8 \mathrm{MHz}$ has been measured by the sweep frequency method at the Democritus Nuclear Station, Athens $\left(38^{\circ} \mathrm{N}, 23^{\circ} 49^{\prime} \mathrm{E}\right)$. Data are published since 1969 in the GSR bulletin Athens and since 1973 in the monthly bulletin at the Atmospheric Physics Laboratory,

-Work carried out at the Atmospheric Physics Laboratory, University of Patras, Greece 
University of Patras, Greece. With a view to study the solar X-ray control of the ionospheric absorption, the sweep frequency absorption data during the period June-July 1969 of maximum solar activity have been compared with the $\mathrm{x}$-ray data from the Solard 9 satellite in the band of 1-8 $\AA$. The degree of solar $x$-ray control of the ionospheric absorption and the corresponding limit of solar $\mathrm{x}$-ray flux have been discussed. It is found that the ionospheric absorption is controlled by solar $\mathrm{x}$-ray only during disturbed conditions with the flux greater than $10 \times 10^{-3} \mathrm{erg} \mathrm{cm}^{-2} \mathrm{sec}^{-1}$ in the band of 1-8 $A$.

\section{Comparison and results}

Although the reflection height of radio signals in the sweep frequency band of 6.3$10.8 \mathrm{MHz}$ is above $250 \mathrm{~km}$, the largest contribution to the ionospheric absorption of radio signals comes from the height range of $60-90 \mathrm{~km}$. Since the solar $\mathrm{X}$-rays are effective below $90 \mathrm{~km}$ in the band of $1-8 \dot{A}$ only, we have compared the sweep frequency noon absorption $L$ with the solar X-ray flux $F_{x}$ in the band of 1-8 A for June 1969 (figure 1) and July 1969 (figure 2). The noon absorption has been obtained as the average of the absorptions measured at 1100,1200 and 1300 UT. The correlation coefficient using linear regression analysis is obtained to be 0.77 for figure 1 and 0.25 for figure 2. Thus the solar x-ray control is better in June than in July as reported and probably explained by Triska and Lastovicka (1970). It is seen from figures 1 and 2 that during quiet-sun conditions $\left(F_{x}<1 \times 10^{-3} \mathrm{erg} \mathrm{cm}^{-2} \mathrm{sec}^{-1}\right)$ the absorption is also large which is explained by some other controlling factors than the solar $\mathrm{X}$-ray.

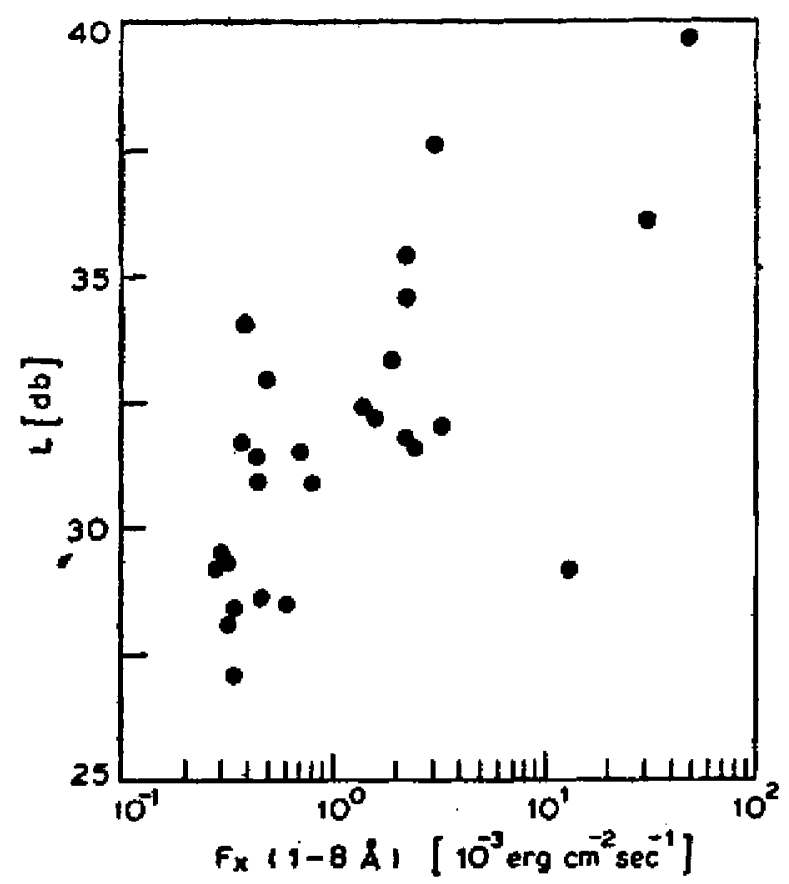

Figwre 1. Correlation of sweep frequency noon absorption with solar X-ray flux for June 1969. 


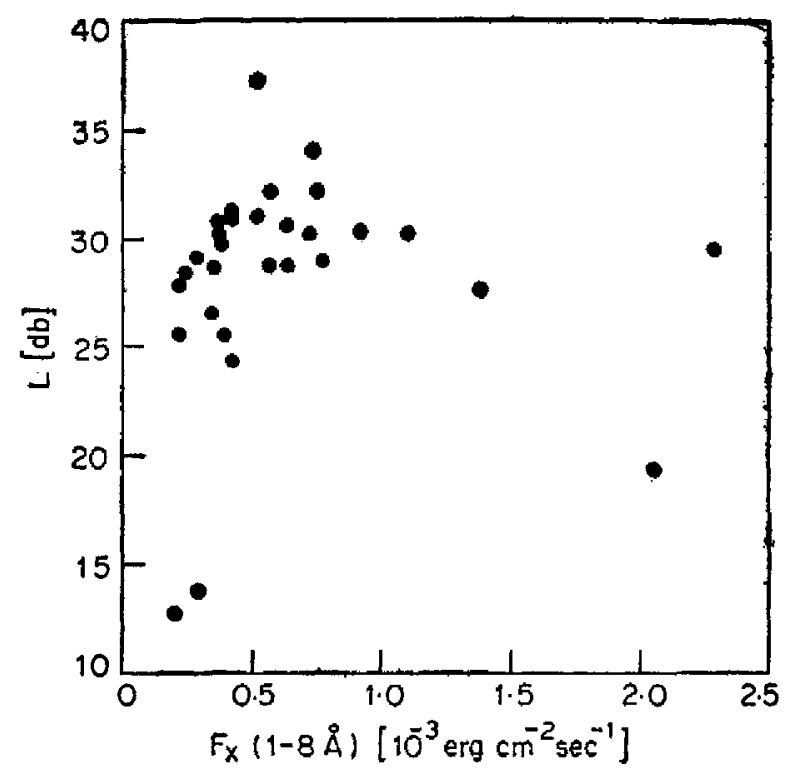

Figure 2. Correlation of sweep frequency noon absorption with solar $x$-ray fiux for July 1969.

The threshold value of $F_{x}(1-8 \AA)$ is found to be $1 \times 10^{-3} \mathrm{erg} \mathrm{cm}^{-2} \mathrm{sec}^{-1}$ for a certain solar $x$-ray influence of the ionospheric absorption. However, the ionospheric absorption is not controlled by solar X-ray in the flux range of $1-10 \times 10^{-3} \mathrm{erg} \mathrm{\textrm {cm } ^ { - 2 }}$ $\sec ^{-1}$.

To estimate the value of $F_{x}$ where the solar x-ray starts controlling mainly the ionospheric absorption, the sweep frequency absorption during a solar $\mathrm{x}$-ray flare (disturbed-sun conditions) of 6 June 1969 in the period of 0950-1030 UT has been correlated with the solar $\mathbf{x}$-ray flux $(1-8 \AA)$ in figure 3 . The $x$-ray flux greater than $10 \times 10^{-3} \mathrm{erg} \mathrm{cm}^{-2} \mathrm{sec}^{-1}$ in the 1-8 $\dot{A}$ band are identified as the solar $\mathrm{x}$-ray flare data. The correlation coefficient is found to be 0.75 for figure 3 . Thus, during disturbedsun conditions the ionospheric absorption is mainly controlled by the solar $\mathrm{x}$-ray in the 1-8 $\mathrm{A}$ band with flux greater than $10 \times 10^{-3} \mathrm{erg} \mathrm{cm}^{-2} \mathrm{sec}^{-1}$, although the influence of solar $x$-ray on the absorption is considerable in the fiux range of $1-10 \times 10^{-3} \mathrm{erg} \mathrm{cm}^{-2} \mathrm{sec}^{-1}$.

\section{Conclusions}

The ionospheric absorption data in the frequency band of 6.3-10.8 MHz measured by the sweep frequency method have been compared with the solar x-ray data in the band of 1-8 $\AA$ during quiet and disturbed-sun conditions of maximum solar activity. As the radio signals are significantly absorbed when penetrating the D-region on the way to the reflecting levels at heights above $250 \mathrm{~km}$ and back, the solar x-ray flux $F_{x}$ in the band of 1-8 $\dot{A}$, effective below $90 \mathrm{~km}$, has been considered. It is found that the solar $\mathrm{x}$-ray control of the ionospheric absorption is mainly for disturbed-sun conditions 


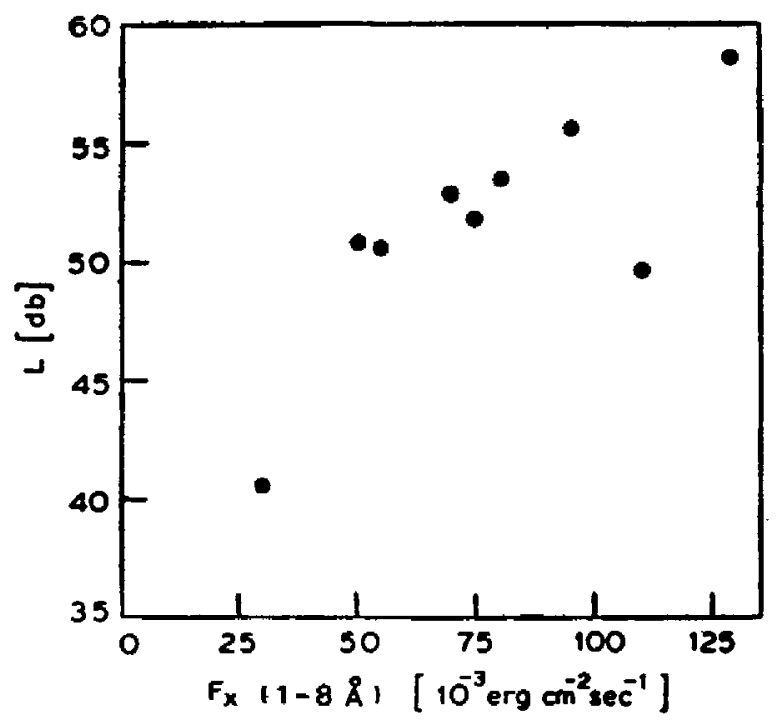

Figure 3. Correlation of sweep frequency absorption with solar $x$-ray flux during a solar x-ray flare of 6 June 1969 in the period of 0950-1030 UT.

with $F_{x}>10 \times 10^{-3}$ erg $\mathrm{cm}^{-2} \mathrm{sec}^{-1}$. During quiet-sun conditions with $F_{x}<1 \times 10^{-3}$ erg $\mathrm{cm}^{-2} \mathrm{sec}^{-1}$, the solar $\mathrm{x}$-ray control of the ionospheric absorption is negligible even at maximum solar activity.

\section{Acknowledgements}

The author is thankful to Professor D J Ilias, Atmospheric Physics Laboratory, University of Patras, Greece for providing necessary facilities, without which the present work would not have been possible.

\section{References}

Deshpande S D, Subrahmanyam C V and Mitra A P 1972 J. Atmos. Terr. Phys. 34211

Ganguly S 1972 J. Atmos. Terr. Phys. 342009

Ilias D J and Gupta G P 1978 J. Atmos. Terr. Phys. (to appear)

Kotadia K M, Chhipa G M and Gupta A 1976 Proc. Symp. Solar Planet. Phys. 4333 (Ahmedabad: Physical Research Laboratory)

Lastovicka J 1973 J. Atmos. Terr. Phys, 35815

Rao D N M and Ramana K V V 1977 Indian J. Radio Space Phys. 632

Triska P and Lastovicka J 1970 Solar Phys. 15504 